\title{
Location Optimization of Hydrogen Refueling Stations in Hydrogen Expressway Based on Hydrogen Supply Chain Cost
}

\author{
Dongxing WANG ${ }^{\mathrm{a}}$, Zhe WANG ${ }^{\mathrm{a}, \mathrm{b}, 1}$, Fenghui HAN ${ }^{\mathrm{a}, \mathrm{b}}$, Fan ZHAO ${ }^{\mathrm{a}}$, Yulong JI \\ ${ }^{a}$ Marine Engineering College, Dalian Maritime University, Dalian, 116026, China \\ ${ }^{\mathrm{b}}$ National Center for International Research of Subsea Engineering Technology and \\ Equipment, Dalian Maritime University, Dalian, 116026, China
}

\begin{abstract}
Hydrogen energy is regarded as an important way to achieve carbon emission reduction. This paper focuses on the combination of the design of the hydrogen supply chain network and the location of hydrogen refueling stations on the expressway. Based on the cost analysis of the hydrogen supply chain, a multiobjective model is developed to determine the optimal scale and location of hydrogen refueling stations on the hydrogen expressway. The proposed model considers the hydrogen demand forecast, hydrogen source selection, hydrogen production and storage and transportation, hydrogen station refueling mode, etc. Taking Dalian City, China as an example, with offshore wind power as a reliable green hydrogen supply to select the location and capacity of hydrogen refueling stations for the hydrogen energy demonstration section of a certain expressway under multiple scenarios. The results of the case show that 4 and 5 stations are optimized on the expressway section respectively, and the unit hydrogen cost is $\$ 14.3 / \mathrm{kg} \mathrm{H}_{2}$ and $\$ 11.8 / \mathrm{kg} \mathrm{H}_{2}$ respectively, which are equal to the average hydrogen price in the international range. The optimization results verify the feasibility and effectiveness of the model.
\end{abstract}

Keywords: hydrogen refueling stations, hydrogen supply chain, hydrogen expressway, location model, cost analysis

\section{Introduction}

Hydrogen has become an important direction of future energy development. At present, hydrogen fuel cell vehicle (HFCV) is the most efficient and production-ready hydrogen technology available [1], and becomes a main direction of hydrogen energy development. However, the lack of complete hydrogen road network and sufficient supporting hydrogen refueling stations (HRSs) are the obvious problems restricting the commercial development of HFCVs. It is estimated that by 2030, there will be 15 million HFCVs and 15,000 HRSs in the world [2]. Despite the rapid construction of global HRSs, the infrastructure of HRSs still faces many challenges [3].

Reasonable location and layout of HRSs can not only make up for the shortage of hydrogen refueling infrastructure, but also have certain practical significance for the construction of hydrogen energy road network. Scholars in various countries have carried

${ }^{1}$ Corresponding Author: Zhe Wang, Marine Engineering College, Dalian Maritime University, Dalian, 116026, China; wang.zhe@dlmu.edu.cn, +86-0411-84729038. 
out relevant studies on the location of hydrogen refueling infrastructure such as HRSs. Some people choose the location of HRSs based on the point demand. Frade et al. [4] applied the set coverage model of point demand to study the location of Aavenidas HRSs, which was implemented in Lisbon. Hadi [5] proposed a two-step modeling and solution to the large-scale maximum coverage location problem, and obtained the optimal resource allocation in downtown Pittsburgh. Nicholas et al. [6] combined the P-median model with geographic information system and applied it to the location of HRSs in California. Different from the point demand model applied by the above scholars, Hodgson et al. [7] applied the flow capture location model (FCLM) and combined the greedy algorithm to locate the site of the HRSs in Edmonton. Kuby et al. [8] applied the actual road network data of Florida to optimize the location problem of HRSs. In order to explore the interaction between the sales volume of HFCVs and the number of HRSs, Yushan et al. [9] solved the integrated optimization model using the capacity constrained FCLM algorithm and the solution process to optimize the location of HRSs. Most scholars focused on a single city or region. Onur et al. [10] studied the set covering constraints to ensure that each area will be covered by the minimum amount of hydrogen infrastructure. Lei et al. [11] combined the classic hydrogen supply chain network design model with the HRSs location planning model. Sungmi [12] proposed an optimization model to effectively determine when and where to build hydrogen production bases and HRSs in urban areas. However, there are few studies on the location of HRSs based on expressways. Besides, the construction of HRSs on expressways can refer to the research of charging stations to some extent $[13,14]$.

Based on the above the hydrogen analysis and the research of HRSs location, this paper focuses on the location of HRSs on the expressway, combines location problem with hydrogen supply chain network design, aims to minimize the total hydrogen supply chain network cost, and develops a multi-objective model based on linear model to determine the optimal size and location of HRSs.

\section{Construction of mathematical model for location of hydrogen refueling stations}

\subsection{Modeling of Location Factors for Hydrogen Refueling Stations}

The hydrogen supply chain mainly includes hydrogen production, storage, transportation, and hydrogen refueling station. Therefore, the total cost of hydrogen supply chain $C$ is composed of hydrogen production $\operatorname{cost} C_{P}$, hydrogen storage and transportation $\operatorname{cost} C_{S D}$, and hydrogen refueling stations $\operatorname{cost} C_{H}$, which is expressed as follows:

$$
C=C_{\mathrm{P}}+C_{\mathrm{SD}}+C_{\mathrm{H}}
$$

The hydrogen production cost is related to the production method of hydrogen and the capacity of HRS, which is shown in the equation (2):

$$
C_{P}=\sum_{i \in N} \sum_{j \in M} p_{j} \times w_{i j}
$$

where $C_{\mathrm{P}}$ is hydrogen production cost, $p_{j}$ is the unit hydrogen production cost of hydrogen source $j\left(\$ / \mathrm{kg} \mathrm{H}_{2}\right)$, and $w_{i j}$ is the mass of hydrogen supplied by hydrogen source $j$ for HRS $i(\mathrm{~kg})$. The hydrogen storage and transportation cost are related to the 
storage and transportation mode of hydrogen, the transportation distance of hydrogen and the capacity of HRS, and its expression is shown in the equation (3):

$$
C_{S D}=\sum_{i \in N} \sum_{j \in M} c_{i j} \times w_{i j}
$$

where $C_{\mathrm{SD}}$ is hydrogen storage and transportation cost, $c_{i j}$ is the unit hydrogen storage and transportation cost $(\$ / \mathrm{kg} \mathrm{H})$ of hydrogen source $j$ supplying HRS $i$, which is calculated according to the distance $d_{i j}(\mathrm{~km})$ between hydrogen source $j$ and HRS $i$, cost index of transportation vehicle $A$ [15] and hydrogen storage and transportation cost index $B$. The expressions are shown in the equation (4):

$$
c_{i j}=A \times d_{i j}+B
$$

The hydrogen refueling station cost is related to the capacity of HRS as follows:

$$
C_{H}=\sum_{i \in N} \sum_{j \in M} c_{h i} \times w_{i j}
$$

where $C_{\mathrm{H}}$ is hydrogen refueling stations cost, $c_{h i}$ is the unit cost of $\operatorname{HRS}(\$ / \mathrm{kg} \mathrm{H} 2)$.

\subsection{Comprehensive Mathematical Model and Hypothesis}

Combined with the above factors of the HRSs location, the model is constructed with the goal of minimizing the total cost of hydrogen supply chain, as shown in the equation (6):

$$
\text { Minimize } C=\sum_{i \in N} \sum_{j \in M} p_{j} \times w_{i j}+\sum_{i \in N} \sum_{j \in M}\left(A \times d_{i j}+B\right) \times w_{i j}+\sum_{i \in N} \sum_{j \in M} c_{h i} \times w_{i j}
$$

with the constraint conditions $F$ below:

$$
F=\left\{\begin{array}{l}
\sum_{i \in N} w_{i j} \leq L_{j}, \quad \sum_{j \in M} w_{i j} \leq w_{i}, \quad \sum_{i \in N} w_{i} \geq D \\
\sum_{j \in M} L_{j} \geq \sum_{i \in N} w_{i}, d_{i, i+1} \leq 200
\end{array}\right.
$$

where $L_{j}$ is the maximum capacity of hydrogen source $j\left(\mathrm{~kg} \mathrm{H}_{2} / \mathrm{d}\right), w_{i}$ is the capacity of HRS $i\left(\mathrm{~kg} \mathrm{H}_{2} / \mathrm{d}\right), D$ is the total hydrogen demand of expressway section $\left(\mathrm{kg} \mathrm{H}_{2} / \mathrm{d}\right)$, and $d_{i, i+1}$ is the distance between adjacent HRSs. Constraint (7) are used to constrain hydrogen demand and station distance of the model, respectively. Based on the above model construction, the hypothesis and applicable conditions are described as follows: 1) expressway is directional and one-way irreversible; 2) when the driver misses a refueling station, he needs to drive to the next station to complete the refueling behavior; 3 ) when HFCVs are hydrogenated, the hydrogen capacity shall not be less than $50 \%$.

\section{Location Selection and Optimization Scheme of Hydrogen Refueling Stations}

\subsection{Key Parameters and Applicable Conditions}

Based on the above mathematical model, the hydrogen supply chain network of the 300 $\mathrm{km}$ section of the expressway from Dalian to Dandong city was designed, and the 
location of HRSs was optimized. As a key input, changes in hydrogen demand have a significant impact on the structure of the hydrogen supply chain [16]. Estimations of hydrogen demand are mainly based on the key parameters such as average daily vehicle mileage per kilometer of expressways, fuel economy of HFCVs and market share of HFCVs. The main parameters and total hydrogen demand are summarized in Table 1.

Table 1. Summary of key parameters of hydrogen demand in expressway section.

\begin{tabular}{ll}
\hline Parameters & Value \\
\hline Total expressway length $(\mathrm{km})$ & 300 \\
The market share of HFCVs $(\%)$ & 5 \\
Roewe950 single hydrogenation $(\mathrm{kg})$ & 4.2 \\
Roewe950 Range $(\mathrm{km})$ & 430 \\
Average daily vehicle mileage per $\mathrm{km}$ of expressway $(\mathrm{veh} . \mathrm{km} / \mathrm{km} / \mathrm{d})$ & 20,000 \\
The total hydrogen demand $(\mathrm{kg} \mathrm{H} / \mathrm{d})$ & 2,930 \\
\hline
\end{tabular}

Based on the characteristics of the fluctuation of offshore wind energy, the method of water electrolysis for hydrogen production in this case is PEM [17]. To estimate the unit cost of hydrogen production, the case study used Hydrogen Analysis Production Models (H2A) developed by the National Renewable Energy Laboratory (NERL) [18]. The relevant information of PEM electrolytic cell and the result of the total hydrogen production cost are summarized in Table 2.

Table 2. Summary of economic parameters of PEM and cost result based on H2A.

\begin{tabular}{ll}
\hline Parameters & Value \\
\hline Hydrogen production scale of hydrogen source $\left(\mathrm{kg} \mathrm{H}_{2} / \mathrm{d}\right)$ & 5,000 \\
Cost of equipment $(\$ / \mathrm{kW})$ & 233.61 \\
Power consumption $\left(\mathrm{kWh} / \mathrm{kg} \mathrm{H}_{2}\right)$ & 51.3 \\
Electricity Price $(\mathrm{Offshore} \mathrm{Wind} \mathrm{Power)}(\$ / \mathrm{kWh})$ & 0.04 \\
Stack life (years) & 10 \\
Total cost of hydrogen production $(\$ / \mathrm{kg} \mathrm{H})$ & 3.02 \\
\hline
\end{tabular}

The cost of hydrogen storage, transportation and HRSs are evaluated based on the Hydrogen Delivery Scenario Analysis Model (HDSAM) developed by Argonne National Laboratory [19]. High-pressure gas and hydrogen transportation of long tube trailers, cascade storage and refueling pressure of $35 \mathrm{MPa}$ at HRSs are considered as key inputs and assumptions in the scenario of HDSAM, and the results are shown in Table 3.

Table 3. The summary of results based on HDSAM calculation.

\begin{tabular}{cccc}
\hline Daily refueling capacity $\left(\mathrm{kg} \mathrm{H}_{2} / \mathrm{d}\right)$ & 500 & 800 & 1,000 \\
\hline Compressed $\mathrm{H} 2$ terminal cost $\left(\$ / \mathrm{kg} \mathrm{H}_{2}\right)$ & 2.2 & 2.2 & 2.2 \\
Cascade storage cost $\left(\$ / \mathrm{kg} \mathrm{H}_{2}\right)$ & 0.49 & 0.49 & 0.49 \\
Compressed $\mathrm{H} 2$ truck cost $\left(\$ / \mathrm{kg} \mathrm{H}_{2}\right)$ & 1.82 & 1.43 & 1.30 \\
Hydrogen storage and transportation cost index $B$ & 4.5 & 4.11 & 3.98 \\
Hydrogen refueling station cost $\left(\$ / \mathrm{kg} \mathrm{H}_{2}\right)$ & 2.92 & 3.04 & 2.69 \\
\hline
\end{tabular}

\subsection{Optimization Scenario Definition}

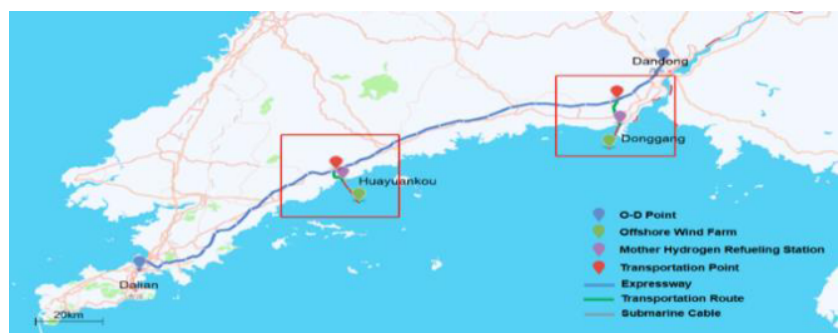

Figure 1. Schematic figure of location about hydrogen sources and transportation nodes. 
On the premise of satisfying the hydrogen demand in the expressway section, two scenarios of single hydrogen source (Huayuankou) and single capacity HRS (800 kg $\mathrm{H}_{2} / \mathrm{d}$ ) and double hydrogen source (Huanyuankou and Donggang) and multi-capacity HRS (500 kg H$/ 2 / d, 800 \mathrm{~kg} \mathrm{H}_{2} / \mathrm{d}, 1,000 \mathrm{~kg} \mathrm{H}_{2} / \mathrm{d}$ ) are selected for optimization. The scale of hydrogen production from hydrogen source is $5,000 \mathrm{~kg} \mathrm{H}_{2} / \mathrm{d}$. The expressway, location distribution of hydrogen sources and transportation nodes is shown in Figure 1.

\subsection{Optimization Solution}

According to the comprehensive mathematical model of hydrogen refueling location and the definition of optimization scenario, the data in Table 1-3 are taken as the key inputs of the model. Combined with the calculation framework Figure 2, the program is written with the help of MATLAB mathematical tools, and the PSO is used to solve the model. Specifically, the case calculates the total hydrogen demand as the demand constraint to determine the number and capacity of HRSs. And the location of HRSs is determined by the driving distance limit. With the help of H2A and HDSAM, the unit cost of hydrogen production, storage, transportation and refueling process is estimated. The above results are used as the inputs of the model, and then the model is optimized and solved.

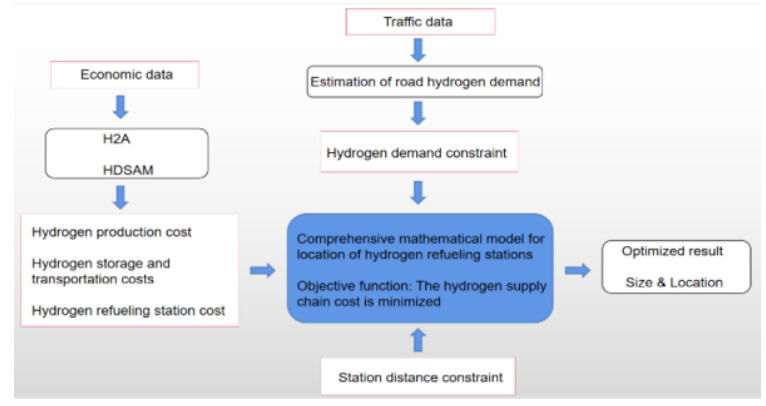

Figure 2. The calculation framework of model.

\section{Optimization Results and Discussion}

The algorithm convergence results under the two optimization scenarios are shown in Figure 3-4. The program running results are sorted out to obtain the optimization results of the location and capacity of the HRSs under the two scenarios, as shown in Table 4. By combining the scenario optimization results with the distribution of hydrogen sources and transportation nodes, the results can be obtained as shown in Figure 5.

According to the results of scenario optimization in Table 4, a total of 4 stations are optimized in S1 on the Dan-Da section of He-Da expressway with a total length of about $300 \mathrm{~km}$. The total daily cost of hydrogen supply chain is $\$ 45,900$, the locations of HRSs are set at $44.8 \mathrm{~km}, 105.2 \mathrm{~km}, 165.3 \mathrm{~km}$ and $225.9 \mathrm{~km}$, respectively, and the unit hydrogen cost is about $\$ 14.3 / \mathrm{kg} \mathrm{H}_{2}$. In S2, a total of 5 stations are optimized and built in the whole section, which are built at $54 \mathrm{~km}, 105 \mathrm{~km}, 151 \mathrm{~km}, 222 \mathrm{~km}$ and $262 \mathrm{~km}$ respectively, and the corresponding daily refueling capacities are $500 \mathrm{~kg} \mathrm{H}_{2} / \mathrm{d}, 800 \mathrm{~kg} \mathrm{H}_{2} / \mathrm{d}, 500 \mathrm{~kg} \mathrm{H}_{2} / \mathrm{d}$, $1,000 \mathrm{~kg} \mathrm{H}_{2} / \mathrm{d}$ and $800 \mathrm{~kg} \mathrm{H}_{2} / \mathrm{d}$ respectively. The total cost of hydrogen supply chain is $\$ 42,500$, and the unit hydrogen cost is about $\$ 11.8 / \mathrm{kg} \mathrm{H}_{2}$. In both scenarios, unit hydrogen costs are in line with the international average selling price of hydrogen. 


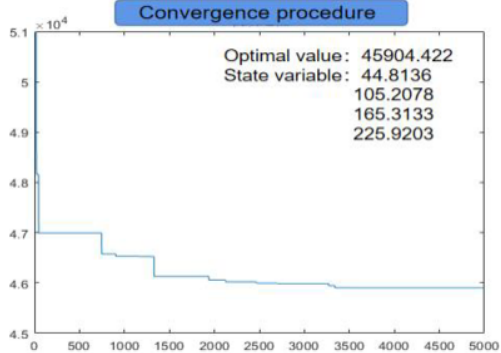

Figure 3. Scenario 1 convergence rendering.

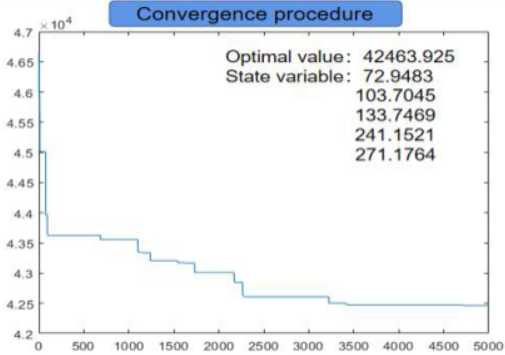

Figure 4. Scenario 2 convergence rendering.

Table 4. Summary of hydrogen sources and transportation nodes.

\begin{tabular}{|c|c|c|c|c|c|}
\hline Scenario & $\begin{array}{l}\text { Daily refueling } \\
\text { capacity }\left(\mathrm{kg} \mathrm{H}_{2} / \mathrm{d}\right)\end{array}$ & $\begin{array}{l}\text { Location of HRS } \\
(\mathrm{km})\end{array}$ & $\begin{array}{l}\text { Hydrogen } \\
\text { source }\end{array}$ & $\begin{array}{l}\text { Total cost } \\
(\$ / \mathrm{d})\end{array}$ & $\begin{array}{l}\text { Unit cost } \\
\left(\$ / \mathrm{kg} \mathrm{H}_{2}\right)\end{array}$ \\
\hline S 1 & 800 & $\begin{array}{c}44.8 \\
105.2 \\
165.3 \\
225.9\end{array}$ & Huayunakou & $45,904.422$ & 14.3 \\
\hline S 2 & $\begin{array}{c}500 \\
800 \\
500 \\
1,000 \\
800\end{array}$ & $\begin{array}{c}72.9 \\
103.7 \\
133.7 \\
241.1 \\
271.1\end{array}$ & $\begin{array}{c}\text { Huayuankou } \\
\text { Donggang }\end{array}$ & $42,463.925$ & 11.8 \\
\hline
\end{tabular}

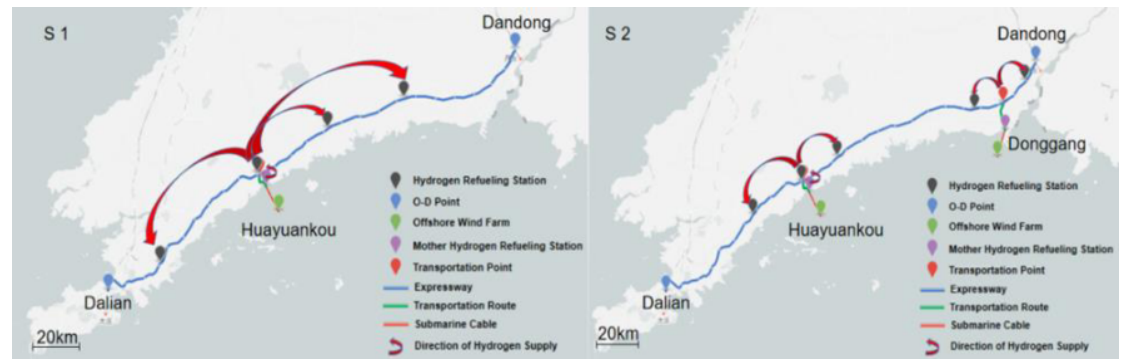

Figure 5. Scenario 1-2: Location optimization result of HRSs.

Different from the difference in economy in Table 4, Figure 5 more intuitively show the distribution of HRSs on the whole expressway section. As can be seen from Figure 5 , compared with the situation that the 5 HRSs are optimized in S2, the positions of the 4 HRSs in S1 are more evenly distributed in the whole expressway section, while the distance between the station 3 and 4 in S2 is larger. Moreover, in S2, HRSs are distributed more obviously centered on transportation nodes. However, in the two scenarios, the location and capacity of HRSs are in line with the relevant constraint settings of the model. Therefore, the optimization results in the two scenarios meet the requirements and the scheme is relatively ideal.

\section{Conclusion}

This paper summarizes the status of the hydrogen industry, starts from the hydrogen expressway and HRSs layout, combines hydrogen supply chain network design and HRSs location, analyses the global to the entire network with hydrogen, and proposes a minimum cost for the purpose of hydrogen expressway with HRSs location universal 
model, in order to promote the development of the hydrogen industry. The proposed method, based on the hydrogen supply chain network with the cost of HRSs location model, can be applied to help an area with hydrogen of an expressway network transform traditional car early transition plan for HFCVs, but with the large-scale development of the hydrogen industry, the model should be combined with the application scenario to make improvement and adjustment, in order to apply to a wider variety of scenarios with more comprehensive and accurate optimization results.

\section{Funding}

This work was funded by the National Natural Science Foundation of China (51906026), China Postdoctoral Science Foundation (2020M680928), Natural Science Foundation of Liaoning Province (2020-BS-067) and 111 Project (B18009).

\section{References}

[1] Jennifer K, Sam S, Thomas H.B. Review of transportation hydrogen infrastructure performance and reliability. Int J Hydrogen Energy. 2019; 44: 12010-12023.

[2] Apostolou, D and Xydis G. A literature review on hydrogen refuelling stations and infrastructure. Current status and future prospects. Sustain. Energy Rev. 2019 Jul; 113: 109292.

[3] Hardman S, Shiu E, Steinberger-Wilckens R, Turrentine T. Barriers to the adoption of fuel cell vehicles: a qualitative investigation into early adopters attitudes. Transport. Res. Pol. Pract. 2017; 95: 166-82.

[4] Frade I, Ribeiro A, Goncalves G and Antunes AP. Optimal location of charging stations for electric vehicles in a neighborhood in Lisbon, Portugal. Transp Res Rec. 2011; 2252(1): 91-8.

[5] Hajari H and Karimi H A. A Method for Large-Scale Resource Allocation in Smart Cities. 2018.

[6] Nicholas MA, Handy SL and Sperling D. Using geographic information systems to evaluate siting and networks of hydrogen stations. Transp Res Rec. 2004; 1880(1): 126-34.

[7] Hodgson MJ, and Rosing KE. Applying the flow-capturing location-allocation model to an authentic network: Edmonton, Canada. European Journal of Operational Research. 2007; 90(3): 427-43.

[8] Kuby M, Lines L, Schultz R, Xie Z, Kim JG and Lim S. Optimization of hydrogen stations in Florida using the flow-refueling location model. Int J Hydrogen Energy. 2009; 34(15): 6045-64.

[9] Yushan L, Fengming C and Lefei L. An integrated optimization model for the location of hydrogen refueling stations. Int J Hydrogen Energy. 2018; 43: 19636-49.

[10] Onur D, Elifcan G, Ebru Y, Rizvan E. Amathematical programming model for facility location optimization of hydrogen production from enewable energy sources. Energy Sources, Part A: Recovery, Utilization, and Environmental Effects, 2020.

[11] Lei L, Herve M and Marie-Ange M. Integrated optimization model for hydrogen supply chain network design and hydrogen fueling station planning. Computers and Chemical Engineering. 2019; 134: 106683.

[12] Sungmi B, Eunhan L and Jinil H. Multi-Period Planning of Hydrogen Supply Network for Refuelling Hydrogen Fuel Cell Vehicles in Urban Areas. Sustainability. 2020; 12(10): 4114.

[13] Pevec D, Babic J and Kayser M A. A data-driven statistical approach for extending electric vehicle charging infrastructure. International Journal of Energy Research. 2018; 42(4): 3102-20.

[14] Qunshan Z, Scott B.K, Fan X and Michael J.K. A multi-scale framework for fuel station location: From highways to street intersections. Transportation Research Part D. 2019; 74: 48-64.

[15] Stevens M.B, Fowler M., Elkamel A, Elhedhli S. Macro-level optimized deployment of an electrolyserbased hydrogen refueling infrastructure with demand growth. Eng. Optim. 2018; 40(10): 955-67.

[16] Lei L, Hervé M and Marie-Ange M. Hydrogen supply chain network design: An optimization-oriented review. Renewable and Sustainable Energy Reviews. 2019; 103: 342-60.

[17] Zexue D and Xuhong M. Development of water electrolysis technology and its application in green hydrogen production. Petroleum Processing and Petrochemicals. 2021; 52(2): 102-10.

[18] H2A: Hydrogen Analysis Production Models. National Renewable Energy Laboratory, 2018. https://www.nrel.gov/hydrogen/h2a-productionmodels.html.

[19] Hydrogen Delivery Scenario Analysis Model (HDSAM). Argonne National Laboratory, 2006. https://hdsam.es.anl.gov/index.php?content=hdsam. 